\title{
Stifling transformation through the manipulation of enrolment: A case study of two public high schools in Gauteng Province
}

\author{
Johan Beckmann and Nic Karvelas
}

\begin{abstract}
This article reports on an investigation into how admission policies in general and the 'zoning' policy in particular are applied by the School Governing Bodies (SGBs) of two particular former Model C secondary schools in a town in the Gauteng Province, Republic of South Africa. It also examines the admission criteria currently in use against the background of allegations that the application of these criteria is a veiled attempt to exclude black learners from schools in order to retain a white learner majority. It also considers what can be termed the 'channelling' of learners. Interviews were conducted with a sample of disgruntled parents, a chairperson of the school governing body (SGB) of one of the schools and the principals of two unrelated schools, which were mentioned during the interviews with the disgruntled parents.
\end{abstract}

Keywords: admission policy, channelling, discrimination, enrolment, manipulation, transformation

\section{Introduction}

In terms of Section 5(5) of the South African Schools Act, 84 of 1996 (SASA, Republic of South Africa 1996a), the school governing body of a public (government) school determines the admission policy of the school. The admission policy must conform not only to the legal requirements of the South African Schools Act, but first and foremost, it must comply with the Constitution of 1996 (Republic of South Africa 1996b) and also with any other applicable legislation.

An admissions policy brochure published by the Gauteng Department of Education in 2004 states that parents should register their children at the school nearest to their homes (Gauteng Department of Education 2004).

Black parents residing in the town in which the schools are situated complain that the 'zoning' policy is abused by the school governing bodies of former Model C schools ${ }^{1}$ and that when they apply to register their children, they are requested to submit a host of documents in order to prove that they reside in the area, only to be told then that the school is full. Consequently, these same parents regard this as an attempt to prevent learners from previously disadvantaged communities from registering at particular schools. A number of parents have accused one of the schools of blatantly manipulating enrolment along racial lines, as even black learners who reside in the area are refused entry to the school.

These parents allege that the policy of registering at a school nearest one's home applies only where black learners are concerned. White learners, they claim, can reside 
anywhere and still gain admission. In addition, parents allege that these schools, apart from generally manipulating enrolment along racial lines, claim to be full as early as August of the year prior to the commencement of the new academic year.

As the research progressed and more data became available, it became apparent that apart from the allegations of enrolment manipulation along racial lines, parents believed that there was a concerted effort by the schools in question to 'channel' black learners to two newly established secondary schools in the same town.

In addition to being a part-time lecturer, one of the authors is the principal of an independent primary school close to the secondary schools in question. He became aware of the allegations during September 2002, when black parents of Grade 7 learners from his school approached him. The initial allegations were repeated each year and prompted the research on which this article reports.

\section{Historical overview}

Prior to South Africa's first democratic elections on 27 April 1994, schools were racially segregated and the central government controlled funds and policy-making. After 1983 three separate education services (termed 'own affairs') (for Indians, coloureds and whites) existed under the tri-cameral parliament in terms of the Constitution of 1983 (Republic of South Africa 1983).

A central government department administered education for Africans (blacks) in 'white South Africa' as a so-called 'general affair'. The central department had some links with, but did not really have the power to govern and demand accountability from, the so-called self-governing territories (a number of geographical areas that were given some measure of self-rule, but not independence, by the apartheid state) and the 'independent TBVC states' (i.e., the Transkei, Bophuthatswana, Venda and Ciskei - four geographical areas in South Africa which were granted and which accepted 'independence' from apartheid South Africa in terms of the policy of apartheid or separate development). The self-governing territories and the TBVC states had their own departments (systems) of education. Each of these various systems operated in virtual isolation. In essence, there were a number of different education authorities which, besides the Department of National Education, included Bantustan departments and four racially defined departments in the areas outside the Bantustans ${ }^{2}$ See Figure 1 , which sets out the organisation of education in apartheid South Africa in simplified terms.

In 1994 the transformation process began with the newly elected government facing the challenge of fulfilling the vision of the Freedom Charter to 'open the doors of learning and culture to all' (Department of Education (DoE) 1995). The charter was conceived by the African National Congress (ANC) and adopted at the Congress of the People in Kliptown near Johannesburg on 26 June 1955. The charter articulates, among other things, the ANC philosophy and policy on how the country should be governed. In addition to the reference to opening the doors of learning and culture the charter contains 


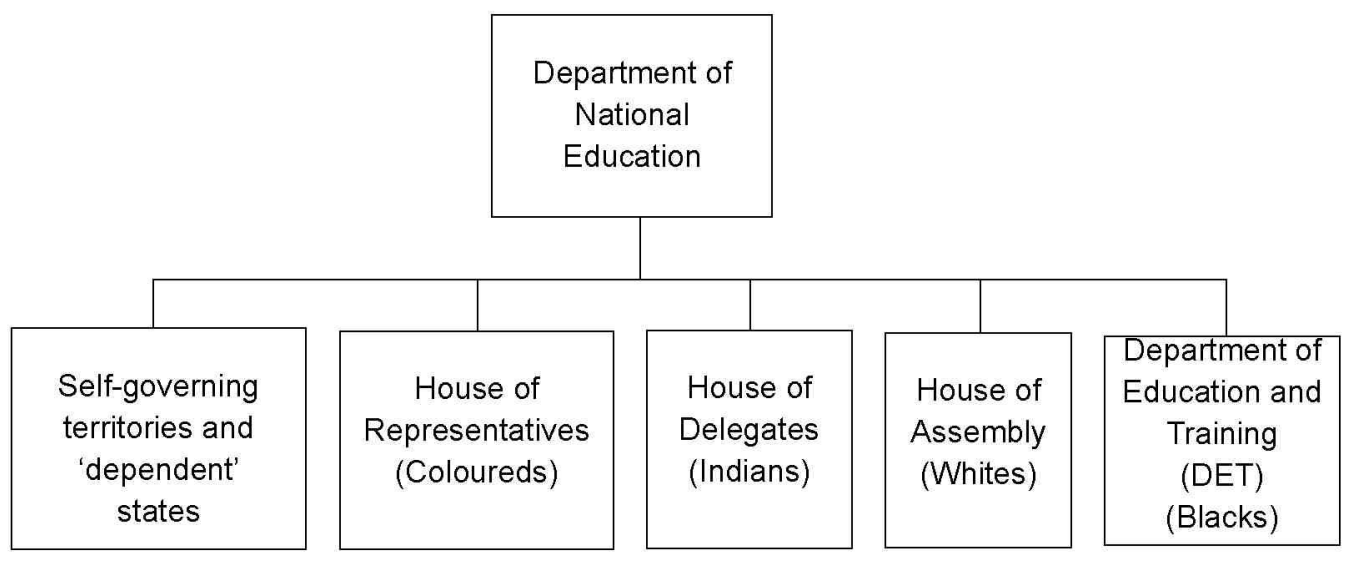

Figure 1: Organisation of the South African education system before 1994

sub-clauses, including the following: the people shall govern, all national groups shall have equal rights, all shall be equal before the law, all shall enjoy human rights and there shall be peace and friendship.

The South African government's ultimate aim was to transform the education system, and indeed all public schools, from unequal and racially segregated institutions into integrated facilities where black, white, Indian and coloured learners, educators and administrators would coexist and work towards a better, and indeed unified South Africa. Government's vision included schools operating as community centres.

However, the aim of transformation was not going to be easy to achieve, and it was going to be contested and those who were going to be instrumental in the process (like governing bodies) were going to come across considerable obstacles. It was never going to be a matter of opening a school door and the door to quality education would automatically open. Governing bodies were called upon to exercise their rights and functions against the backdrop of a broad-ranging debate that simultaneously empowered and impaired them.

In the negotiations on the education governance model before 1994, the tension between the notions of centralisation (the concentration or merging of functions in one body, especially as regards administrative and control function) (Human Sciences Research Council 1981, par. 5.2.4.11) and decentralisation (the distribution, delegation, allocation of functions related to administration or management; granting such functions to subsections of a whole) (Human Sciences Research Council 1981, par. 5.2.4.1) was prominent from the start. This tension has been recorded extensively, among others, by Beckmann (2002), Beckmann and Visser (1999), Fleisch (2002), Malherbe (in de Groot et al. 1997), and Sayed (2000). This means that, in exercising their right to determine an admissions policy for their schools, school governing bodies were inevitably caught up in the politics of the protagonists of centralisation (namely the ANC and its allies) and 
decentralisation (the NP and its allies) and both sides of the divide could foreseeably criticise a governing body for either opening up admissions so much that the notion of quality education could be threatened or for restricting admission to an extent that amounted to indirect and unfair discrimination against certain learners.

Moreover, school governing bodies have to contend with other real problems such as a lack of facilities, a lack of teachers and a lack of clear guidelines on how to determine admissions requirements and on the contents of such guidelines. We are therefore arguing against a unilateral and over-simplified notion that school governing bodies choose to act either as villains or as heroes in the quest to transform schools and to open access to schools that were formerly homogenous in terms of the racial composition of learners. In terms of their powers and resources there is much that they can do to open up access but these very powers and resources may also impede them.

Although everyone has the right to a basic education (and with it the right to access to public educational institutions) (Section 29 of the Constitution) (Republic of South Africa 1996) one needs to notice that the right (like all other rights in the Bill or rights) is not boundless and that it is indeed subject to limitation in terms of the internal qualifiers in the rest of Section 19 and also the Limitations Clause on Section 36 of the Constitution). The limitation of a fundamental constitutional right is a serious issue and has serious implications for both decision makers and those affected by their decisions. As regards admission, the onus is on school governing bodies to regulate admission in such a way that it will support the fundamental right to education without losing sight of the context in which they operate. The requirement that they should not discriminate unfairly directly or indirectly remains firm. It is however, also true that the lens one focuses on a particular admissions policy or related incident will, to a large degree, influence one's opinion on the legality and even legitimacy of the policy or action in question.

\section{Transformation in practice}

The White Paper on Education and Training (Department of Education 1995) clearly set out the goals, policies and intentions of the DoE to integrate and transform the organisation, governance and funding of the education system. The adopted transformation and integration slogans and policies of the government raised the expectations of millions of black South Africans who were hopeful that their children too would now have the opportunity to be educated in a system with well-equipped schools, as previously only whites had been privileged to do.

One would, however, have had to be extremely naïve to believe that all the schools that had once been reserved for whites and were situated in former 'whites-only' suburbs, would suddenly open their doors to welcome black learners. As much as some former Model C schools took up the challenge, and adopted the policy and vision to integrate and transform their schools, this step was not always taken willingly everywhere and, in fact, integration had to be officially imposed on a number of schools. Some schools' unyielding opposition to transformation is confirmed in the Report of the Ministerial 
Review Committee on School Governance (Department of Education 2004, 123):

What is obvious is that there are schools that go out of their way to admit learners in the spirit of the Constitution, to ensure that the doors of learning are opened to all. There are also those that use subtle and less subtle methods to keep their schools exclusive. The effect is discrimination against poor and illiterate parents. Although they have the legal right to demand places and to complain to the Head of Department for relief, many go away helplessly, never to return.

In addition, in honouring the principles of the Freedom Charter, and specifically in regard to opening the doors of learning and culture to all, the Minister of Education, Naledi Pandor (MP), ${ }^{3}$ during her parliamentary address at the time of the Education Budget Vote debate in the National Assembly in May 2005, referred to 'door three' as the door associated with, inter alia, school governing bodies, and stated:

The third door is one to which the powerful people on school governing bodies (SGBs) keep the keys. These bodies tend to be very selective in opening the door to some and keeping it closed to others. There are some 200000 individuals on SGBs. They have the power to set admissions policy, to determine what language or languages will be used in schools and to assist parents set with setting fees. To the majority of them, I say thank you for your dedicated service and commitment to the children of our country. Sadly, others ruin the good work. Instead of supporting the school sector in promoting access, democratisation, and quality, they have made public schools their personal property.

Naturally the minister is entitled to her views and her allegation that governing bodies tend to be very selective in opening the doors of learning to some was one of the factors that encouraged us to embark on this modest empirical investigation to begin to understand the allegations better. The minister gave no indication of the scope of the problem she highlighted and the nature of our investigation was not quantitative. However, we believe that we have found enough qualitative evidence to put forward an hypothesis for a more comprehensive investigation that some governing bodies may indeed be deliberately trying to keep the doors of learning closed to some learners (notably black learners), thus also interfering with the transformation of education. As black parents attempt to enrol their children in former white or Model C schools, so school governing bodies of some of these schools seem to use the powers and functions conferred on them by the School Act to attempt to retain the status quo, endeavouring to keep a white majority of learners and educators in those schools.

As a result, many black parents who are manifestly interested in the best possible education for their children, are becoming increasingly frustrated. This was evidenced at a number of schools in the Gauteng Province and elsewhere at the beginning of the 2005 academic year, with the unfolding of a highly publicised hostage drama in Potchefstroom in the North West Province, when an irate parent held four public school staff members hostage at gunpoint. In another town on the East Rand parents refused to leave the premises of two secondary schools until their children were officially registered at the schools. 


\section{The South African Schools Act and admissions}

Section 5(5) of the South African Schools Act compels the governing body of a public school to determine the admission policy of that school, which may in no way discriminate unfairly against learners. In determining the admission policy the school governing body of a school should also be guided by policies adopted by education departments in both the provincial and national spheres of government. Admissions policies should also comply with any other applicable legislation.

In 2004 the General Education and Training Directorate of the Gauteng Department of Education published an information booklet entitled 'Admission of learners into public schools' (Gauteng Department of Education 2004). The aim of the booklet is to assist parents and guardians in registering their children at schools in the Gauteng Province. Besides informing parents and guardians of their rights, the booklet contains other useful information, including the 'Main steps in admission' (Gauteng Department of Education 2004, 3, item 1). It also instructs parents and guardians to 'register your child at a school nearest to you'.

There can be no doubt that under normal circumstances learners should attend the school nearest their home. This, in fact, is the norm in many countries around the world.

1. The admission policy for the London Borough of Redbridge in the United Kingdom, ${ }^{4}$ for example, refers to a catchment area as 'the area around a school covering a number of roads or parts of roads'. It further states: 'Living in a catchment area gives you higher priority for admission to the school but does not guarantee entry and, please note, places can be withdrawn if you give false information about where you live, on your application form.'

2. The Elk Island Public Schools in Alberta, Canada have, through the relevant legislation or Schools Act, created School Attendance Boundary Maps where 'students are assigned a designated school, which is usually their neighbourhood school, depending on school capacity and utilization.'

In terms of this legislation and the admissions policy, parents and students can apply to attend any Elk Island Public School through what is known as the Boundary Exemption System. ${ }^{5}$

South Africa is, however, unique in that schooling was racially segregated for decades, with the white schools in the suburbs receiving far more funding per learner than the black schools in the former townships. Since South Africa's transition to democracy and the demise of apartheid, increasing numbers of black parents have sought to register their children at former Model $\mathrm{C}$ schools in the suburbs, which they perceived to be good schools.

Even though many changes have taken place in South Africa during the past decade, 
there has been no significant demographic and socio-economic change. The majority of black South Africans continues to reside in the former townships and the suburbs continue to be inhabited mostly by whites.

Lone Poulsen, professor at the School of Architecture and Planning at Johannesburg's University of the Witwatersrand, in an interview with News $24^{6}$ stated that a real change in the demographic pattern of cities was 'light years away'. She said that the racial divide had given way to an economic divide and that the basic apartheid framework of blacks and coloureds living in townships on the outskirts of cities would survive for a long time, as 80 per cent of the population was poor and could not afford to live elsewhere.

As a result of the lack of demographic and socio-economic change, any policy which attempts to limit learners to schools nearest their homes, runs the risk of re-entrenching segregation. Ideally, such a policy should be adopted only once the inequalities of the education system and schools have been addressed adequately. A reviewer aptly remarked that this assumption is a minefield of hidden assumptions, among others, about what is adequate, who decides and whether the concept of inequality is defined in terms of the entire school system in South Africa or only in terms of former Model C schools.

\section{Research methodology}

Interviewing appeared to be the most appropriate manner in which to collect the information required, since it enables respondents to discuss their interpretations of their life-world, and to describe their own perspectives on situations. In this sense an interview is not concerned simply with collecting data about life: it is part of life itself, its human embeddedness is inescapable (Cohen, Manion and Morrison 2002, 267). Interviews were held first with the parents concerned and then with other role players of the schools involved.

Initially three disgruntled parents, one guardian (referred to as parent A) and the aunt of a learner who had reported allegations of racism against the secondary schools in question to the principal of the primary school their children attended, were interviewed. The principal in question is one of the authors of this article and had received complaints from four parents of Grade 7 learners at his school in 2002, 2003 and 2004 regarding the manipulation of enrolment along racial lines by two former Model C secondary schools.

The interviews conducted with the four parents individually over a period of two weeks in January 2005 were tape-recorded.

The interviewees were all asked the same open-ended question, namely to relate their experiences regarding their attempts to enrol their children at the schools in question. Additional questions were asked only when clarity was required in regard to a particular point or response. 
After the recordings had been transcribed, the data were categorised and coded. In order to corroborate the different responses from the parents and to report accurately on the findings, it was necessary to seek common traits in the responses.

Once the interviews with the parents had been conducted, the two former Model $\mathrm{C}$ schools concerned (those mentioned by the parents during the interviews) were contacted to arrange interviews with their SGB chairpersons.

Only one of the SGB chairpersons was prepared to be interviewed and to respond to the parents' allegations. A semi-structured, telephonic interview was conducted with the school governing body chairperson and all the questions asked related specifically to the parents' allegations. After the interview had been recorded and transcribed, the responses were categorised, coded and linked to the parents' allegations.

\section{Findings}

\section{Allegations of racism levelled against the schools}

As previously mentioned, the schools in question ${ }^{7}$ are two established secondary schools in the suburbs of a town in the Gauteng Province. High school A is a parallel-medium (Afrikaans and English), co-educational school with approximately 1500 learners. High school B is an English-medium, co-educational school with 1070 learners.

In the case of high school A, three of the parents alleged that they were informed that the school was full when they enquired about enrolment in August of the year prior to the learners' proceeding to Grade 8. The fourth parent was led to believe that Afrikaans was the only medium of instruction at the school. He did not elaborate and his opinion could have been based solely on his personal perception.

Parent A was informed that the school was full, despite the learner in question residing in a suburb situated approximately a kilometre from the school and within the so-called 'feeder' area.

Parent B was also informed that the school was full and accused the administrators at high school A of being extremely rude and unhelpful. He furthermore claimed that it was clear to him that blacks were not welcome and that only a select few were accepted in order to create the impression that the school was integrated.

When parent $\mathrm{C}$ enquired about registering his son at high school $\mathrm{A}$ in 2004, he was told to collect the forms at the school on a specific date. He claims that on the day he went to fetch the forms he was told to wait and that someone would attend to him shortly. He alleges that after an hour he had not yet been attended to, while white parents who arrived left with application forms.

Parent $\mathrm{C}$ approached the administration staff and protested about the fact that he was made to wait. After a heated argument a male educator was called. The argument 
continued and parent $\mathrm{C}$ informed the male educator that his treatment smacked of racism. The male educator then allegedly informed parent $\mathrm{C}$ that the school was full.

Parent $\mathrm{C}$ lodged a formal written complaint with a senior manager at the Gauteng Education Department. Consequently, he was afforded a meeting with the school principal who supplied the relevant application forms. A few weeks after applying, parent $\mathrm{C}$ received a response indicating the school's 'regret' at being unable to accommodate his son. Despite the fact that parent $\mathrm{C}$ also resides in a suburb in the town in question, his son travels to a school in another town.

Three of the parents/guardians who were turned away from high school A approached high school B, which is situated approximately two kilometres from high school A.

Parent A was initially informed that the school was full and that the name of the learner concerned would be placed on a waiting list. She was requested to submit a water and electricity bill to prove that she did indeed reside in the 'feeder' area. In addition, owing to the fact that the learner is her nephew, she had to submit an affidavit from her sister confirming that the learner did indeed reside with her. Parent A travelled to Mpumalanga where her sister lives in order to fulfil this requirement and claims that three weeks after she had applied and after the learner's name had been placed on a waiting list, a white learner from her nephew's primary school class applied and was accepted immediately.

Parent B claimed that when he applied at high school B, he was informed that the school was full. He was further informed that there was a recently established secondary school, a former Model C primary school in another suburb of the town, and that he should register the learner there.

Parent D, who resides in a former township, applied at high school B and was informed that the school was full and that the learner's name would be placed on a waiting list. As he was aware that he would need to verify that he resided in the 'feeder' area, parent D arranged to use the address of a friend whose house was registered in a close corporation. In October 2004 parent D was informed that his daughter could not be registered at the school. He too, like parent B, was advised to register her at the recently established secondary school.

Parent D claimed that only black parents are referred to the recently established school and to another secondary school in a different part of town, which appears to have only black learners registered.

It was parent D who raised the issue of what can be referred to as 'learner channelling'. Parent D could not understand why it seemed that only black learners attended the recently established secondary school, a former Model C primary school. Why were the white learners who resided close to the recently established secondary school not referred there by high school A and high school B? Was it only black learners who were referred to the two aforementioned secondary schools in the suburbs of the town? 
With regard to the Gauteng Department of Education policy that learners should register at the school nearest to their homes, parent $\mathrm{D}$ claimed that he had gone to great lengths to register his child at a former Model $\mathrm{C}$ suburban school, as the school nearest to his home lacked facilities, and a culture of teaching and learning was prevalent in former Model C schools. This, he believed, was due to the legacy of apartheid.

He furthermore commented that Gauteng Department of Education officials, who were attempting to implement a 'zoning' policy, no longer resided in the townships and were no longer in touch with the realities of township education. As far as he was concerned, all public schools should be accessible to all, regardless of social standing or demographics.

\section{The schools respond}

Once the disgruntled parents had been interviewed, the principals and school governing body chairpersons of high schools A and B were asked to respond to the parents' allegations.

Since the principal of high school A did not respond to a written request for an interview, a number of telephone calls were made to elicit a reply. Eventually, the principal returned the call, declining the invitation for herself and the school governing body chairperson to be interviewed. In addition, she indicated that the school's admission policy was in line with the policy of the Education Department and that there was no racism at the school.

The principal was informed that a number of parents had accused the specific school of manipulating enrolment along racial lines and that certain issues required clarification. As requested by the principal of high school A, a set of written questions was e-mailed to her. A written response from the school governing body chairperson of high school A stated, among other things that: 'The Management Committee of the Governing Body has discussed your request for information and after consultation with our representative at the Gauteng Department of Education, decided not to comment on the request.'

The reluctance of the principal and school governing body chairperson of high school A to grant an interview resulted in a quest for information about the specific school from other sources. We surmised that the information thus obtained could well contribute to the emergence of a relatively well-defined picture of the situation in the schools concerned.

In an interview, the school governing body chairperson of high school B confirmed that the school enrolled learners from all the suburbs in the town as well as from the township. It must be pointed out that this in itself indicates the former township is not viewed as a suburb of the same town, but rather as a totally separate town. The school governing body chairperson confirmed that there are 1070 learners at the school, of whom approximately 30 per cent are black, and that the policy of accepting learners from the areas nearest to the school is indeed enforced. He furthermore confirmed that 
the school carries out regular physical checks and that the addresses on the enrolment forms are visited to confirm that a learner does indeed reside at the stipulated address, that is, an address in the 'feeder' area.

This, however, contradicts the initial claim that learners from the township are admitted. If indeed the policy of enrolling learners from the areas nearest the school or 'feeder' area is enforced through the physical checking of the addresses on the application form, why were learners from the former township accepted? The school governing body chairperson of high school B initially confirmed that township learners were enrolled at the school.

He furthermore confirmed that the school was full for the following year by September of the preceding year. This, he advised, was due to the fact that the school, initially built to accommodate approximately 750 learners, was now accommodating in excess of 1000 learners.

He believed the solution to the problem would be to upgrade the schools in the former townships so that black parents could enrol their children at schools nearest to their homes in line with the Gauteng Education Department policy.

We probed the point raised by parent $\mathrm{D}$, namely the 'channelling' of black learners to two specific secondary schools in the town and, more importantly, why white learners who lived in close proximity to said schools were not referred there by high school B as well. The principal responded that his school could select the best learners from a vast list of applicants. This, however, appears to be in conflict with the statutory requirements of South African Schools, Act, 84 of 1996, which clearly states under Section 5(1) that: 'A public school must admit learners and serve their educational requirements without unfairly discriminating in any way.'

As a result of the allegations made by parent $\mathrm{D}$ about 'channelling' learners, the principals of the two secondary schools mentioned were contacted and interviews were conducted. These schools will be referred to as high school C and high school D.

The principal of high school C, a suburban school in the town, confirmed that the learner enrolment at the school comprises 99 per cent black learners. Questioned about why white learners who reside close to the school do not attend this school but are enrolled at schools further from their homes, the principal advised that she was new to the school and the area and did not know how many school-going white learners there were in the area. She said she was therefore unable to comment.

The principal of high school D, established on the premises of a former Model C primary school, which had moved to premises that had been vacated by an Afrikaans primary school approximately a year before, confirmed that his school had an enrolment of 99 per cent black learners. On being asked about the former Model C secondary schools in the town referring only black learners to his school and retaining white learners regardless of their area of residence, he confirmed that no white learner had 
been referred to his school by a former Model C secondary school. He agreed that it would definitely appear as if they were retaining white learners and channelling black learners to his school. He informed the interviewer that: 'We currently have only one white learner at our school and his parents are looking for another school to transfer him to'.

Naturally, we would have been able to draw a more accountable and contextualised conclusion if the governing bodies were more willing to provide us with 'their side of the story'. We had to rely heavily on parents' versions of what happened. We had no documents such as application forms, dates of submission, notices that admission had been denied and the reasons for denial to help us arrive at a conclusion based on richer and more nuanced data. It is quite possible that some or most or even all of the parents' allegations may be viewed differently judged from another evidence base. It is also possible that parents may have led schools to believe that they were acting within their rights to refuse admission to the learners in questions. Again, our investigation never pretended to be a comprehensive one, which could have led to more accountable conclusions. Such conclusions will only be forthcoming from a more comprehensive investigation than the one we conducted. And it will also have to be an investigation in which all the role players take part to provide the data needed.

\section{Comments}

The South African Schools Act was the result of negotiation and compromise, which set the stage for school transformation after South Africa's first democratic elections in 1994. After 300 years of segregation the newly elected ANC-led Government of National Unity was required not only to dismantle the segregation that was synonymous with the preceding decades under apartheid rule, but also to face the unenviable task of integrating and transforming society in general. Education posed one of the greatest challenges to the fragile democracy in South Africa and was clearly one of the most volatile areas, which needed to be transformed post haste.

As has already been mentioned, many former white Model $\mathrm{C}$ schools accepted the challenge of transformation and integration. These schools, which were progressive in their thinking, realised that it would benefit society as a whole, and the youth in particular, if transformation and integration took place in their schools sooner rather than later. It was, however, unavoidable that certain former white schools would attempt to maintain the status quo and ensure that their schools remained predominantly white.

This attempt to retain the status quo may be ascribed to the existence in these schools of deep-rooted prejudices and a fear that black learners would swamp former white schools. They believed that this would inevitably alter the ethos of the school and that standards would plummet. This fear may have been fuelled by, among other things, the provision during the school reforms initiated by the former National Party government in the early 1990s that, if black learners were allowed to enter former white schools and become the majority, the 'classification' of the school would change, with several detrimental effects regarding autonomy and funding. 
In terms of section 9 of the Constitution of 1996 unfair discrimination, be it direct or indirect, is prohibited. The South African Schools Act also prohibits it explicitly (e.g. in sec 5). We have, however, found strong evidence of attempts by former Model $\mathrm{C}$ schools to retain a white learner majority through the manipulation of the relevant education legislation. Despite the covert and subtle manner in which this is done, it nevertheless constitutes unfair discrimination. It needs to be remembered that the nature of our investigation limits us to commenting on the schools in question 9, and that we cannot and do not want to generalise. In addition, the nature of our investigation did not allow for the verification of allegations that white learners (apparently known to black learners) were admitted after black learners had been told that the schools were full. We believe, however, that we have succeeded, to a large extent, in generating a hypothesis for further research, namely that former Model $\mathrm{C}$ schools that want to retain their exclusive status are able to do so by manipulating enrolment provisions.

During this research, it became apparent from data collected during the interviews with disgruntled parents, and additional information gleaned from numerous sources, that high school A, an almost exclusively white public school, appears to manipulate enrolment provisions. It was established during a meeting with the former principal of high school A late in 2002 that the enrolment at the time was approximately 1500 learners, including 68 black learners. In other words, a mere 4,5 per cent of the total learner enrolment was black.

Apart from the fact that this ratio in itself would signal enrolment manipulation, the same school principal also confirmed that white learners were transported to the school by bus from areas outside the town. It furthermore appears that, bar a few exceptions, white learners are registered at the school regardless of the area in which they reside, while black learners are refused admission. It therefore appears that the policy of 'zoning' and registering at a school nearest one's home is applied mainly to black learners.

It would furthermore appear that this school declares itself 'full' for the following academic year in August of each preceding academic year. This raises significant questions such as how schools manage to disregard clear departmental instructions aimed at protecting learners' right to admission as well as how districts can tighten up their supervision of schools regarding admission and play a greater role in the protection of learners' rights. Information made available by the school district in question has established that legally speaking, a school is full only once the District Senior Manager of the Gauteng Department of Education declares such a school full. It is highly unlikely that this would be the case during the first month, and in the case of parent $\mathrm{C}$, the first day, of registration and prior to the tenth day registration statistics having been calculated and received by the Gauteng Education Department. The department's District Office in which these schools are situated has confirmed that only the District Senior Manager can declare a school full, and that this is done only after the specified registration period has elapsed and the relevant enrolment information has been received from the schools concerned. One reviewer commented correctly that this arrangement is almost impossible to implement, for example by preventing schools from turning away learners 
until the provincial department has processed statistics. It begs the question as to how schools do logistical planning, staff and subject allocation, book orders, budgeting, as soon as legally required in the fourth quarter if they have not more or less finalised school numbers. Clearly the system needs to allow schools the scope to determine capacity within some parameters. However, schools that declare themselves full may be guilty of illegal action and liable to action until the system is changed.

A common factor that emerged during all the interviews with the parents and guardians was that both schools claimed to be full. In every instance the parents and guardian were informed that the schools were full as early as August or September of the year preceding the commencement of the next academic year. This is in clear violation of the Gauteng Department of Education regulations pertaining to admissions.

It would appear further, as was the case with parent A, that black parents are informed that the school is full, yet when a white parent applies, there is a vacancy. This implies that places at these schools are reserved for white learners. A reviewer made a point that evidence from case studies could be used to prove or disprove this assumption in individual cases. This specific reviewer seems to agree with our point of departure that we should not try to generalise on the basis of our evidence. We agree with the reviewer that our admittedly limited conclusions on a possible problem pose the need for further research, for example a structured questionnaire that does not leave responses to impressions or perceptions and evasive answers, but tries to establish exact evidence about dates, cut-off points, procedures for handing out and receiving application forms, dates by which acceptances are issued, policy about waiting lists, and procedures for handling late applications. Such research should also try to explore concepts such as stifling, channelling and zoning, and their importance in contexts where there are deliberate efforts to change the racial composition of learner bodies.

In the case of high school B it would appear that, even though the school is attempting to transform and integrate, there are attempts to manipulate enrolment along racial lines and to ensure that the majority of learners is white. It furthermore appears that high school B 'channels' black learners to two specific secondary schools in other suburbs of the town, while retaining white learners. This can be construed as indirect discrimination.

It would appear that the school governing bodies of both schools stretch the boundaries, not only of the powers vested in them by the South African Schools Act (Department of Education 1996a), but also of the policy that stipulates that learners must enrol at schools nearest their homes. Whether this policy would withstand a legal challenge is questionable. Is it legally possible to force parents who reside in a former township to enrol their child at a public school nearest their home when that school may not be on par with a former Model C public school in the suburbs? From a legal perspective it would in all probability be impossible to exclude a learner from a specific public school unless the school is full, and for no other reason.

The Gauteng Department of Education deserves to be criticised for failing, firstly, 
to give clear guidelines regarding the policy of 'zoning' and, secondly, for seemingly failing to act against schools that abuse both the 'zoning' policy and their powers in terms of the Schools Act.

The entire policy of registering learners at a school nearest their homes needs to be revisited. After ten years of 'democracy and freedom' there has been no significant socio-economic and demographic change to justify such a policy. Black people continue, to a large extent, to reside in former townships and former 'white only' suburbs continue to be populated mostly by whites.

Black parents who view schools in the former townships as inferior to the schools in the suburbs continue to enrol their children in suburban schools where possible. This in itself sets the stage for a continuous struggle between increasingly frustrated black parents and school governing bodies in former Model C suburban schools, which appear, through enrolment manipulation, to be attempting to retain a white majority learner complement.

\section{Recommendations}

As a result of the establishment of school governing bodies the South African Schools Act was instrumental in decentralising educational control. Although it is unlikely that the legislators' intention was for school governing bodies to be empowered to retain the status quo as far as racial segregation was concerned, it seems that, in order for genuine transformation to be speeded up, government may consider further centralisation of educational control. This raises vexing questions about, and may seem to be in conflict with, declared educational policy (such as the White Paper of 1995 (Republic of South Africa 1995)), decentralisation, parents' rights, school funding and even the values underpinning the Constitution of 1996.

The Gauteng Department of Education should be far more assertive in handling these issues, and needs to act against schools that manipulate enrolment along racial lines. Is it possible that a public (government) school in South Africa, after 11 years of 'democracy and freedom', can have a black learner complement of only 4,5 per cent or 30 per cent, without manipulating enrolments? At present the policy in question seems to be entrenching segregation in South African schools, if not only along racial lines, then along socio-economic lines, which are linked to race.

The Gauteng Department of Education should, in the case of suburban secondary schools, such as high school A and high school B, that declare themselves full as early as August preceding the start of a new academic year, and are unable to accommodate even the learners that reside in close proximity to the school, consider increasing the number of classrooms and other facilities by utilising open spaces which are underutilised. The department could, furthermore, investigate whether it would be feasible to increase the classroom and other facilities where there is space available at established former Model $\mathrm{C}$ schools, rather than to upgrade schools in the former townships. As a reviewer suggested, this last recommendation may be begging the 
question of what it is that ensures quality in any school and to what extent the changing of demography is the primary variable in school quality.

\section{Conclusion}

Changing the democracy of school populations in South Africa will almost certainly have a positive impact on society as a whole and ultimately contribute to a united South Africa. As much as such change has been embraced by many South Africans, there are clearly pockets of resistance within the education system. Until such time as this resistance, among other things, related to zoning, channelling and the learner populations of schools, is identified and overcome, the doors of learning and culture that should by now have been opened to all, will remain half closed.

\section{Notes}

1 The term refers to former white public schools that elected during the 1990-1994 period to change their admission policies to enable them to enrol learners from all racial groups.

2 The word was used to refer to both the self-governing territories and the TBVC states.

3 http:/www.education.gov.za/mainSpeech.asp

4 http://www.redbridge.gov.uk/tookit/publication.cfm/133/showone

5 http://www.schoolfinder.com/schools/profile.asp\%3FProfileType\%3DPubli

6 http://www.news24.com/News24/South_Africa/Decade_of_Freedom/0,,2-7-15

7 Names withheld for purposes of confidentiality.

\section{References}

Beckmann, J. L. and P. J. Visser. 1999. Some thoughts on the legal position and role of governing bodies of public schools in the new educational environment. Journal for contemporary Roman-Dutch Law 62 (1): 108-113.

Beckmann, J. L. 2002. The emergence of self-managing schools in South Africa. Education and the Law 14 (3): 153-166.

Cohen, L., L. Manion \& K. Morrison. 2002. Research methods in education. London and New York: Routledge/Falmer.

Department of Education 1995. White Paper on Education and Training. Pretoria: Department of Education. 
2004. Report of the Ministerial Review Committee on School Governance, 2004.

Pretoria: Department of Education.

Fleisch, Brahm. 2002. Managing educational change: The state and school reform in South Africa. Johannesburg: Heinemann.

Gauteng Department of Education 2004. Admissions of Learners into Public Schools (Brochure). Johannesburg: Gauteng Department of Education.

Human Sciences Research Council. 1981. Principles for the provision of education in the RSA. Pretoria: Human Sciences Research Council.

Malherbe, Rassie. 1997. The education clause in the South African Bill of Rights: Background and contents. In Human Rights in South African education: From the constitutional drawing board to the chalkboard, eds. J. de Groot and R. Malherbe. Levren: ACCO.

Republic of South Africa 1983. Constitution of the Republic of South Africa, 110 of 1983. Pretoria: Government Printers.

1996. Constitution of the Republic of South Africa. Pretoria: Government Printers.

. 1996a. South African Schools Act No. 84 of 1996. Pretoria: Government Printers.

Sayed, Yusuf. 2000 discourses of the policy of educational decentralisation in South Africa since 1994: An examination of the South African Schools Act. Compare:141-152. 